\title{
Immunomodulatory effects of mesenchymal stem cells in peripheral nerve injury
}

\author{
Xiangling Li ${ }^{1,2,4}$, Yanjun Guan², Chaochao Li², Tieyuan Zhang ${ }^{2}$, Fanqi Meng ${ }^{2,5}$, Jian Zhang ${ }^{2}$, Junyang Li ${ }^{2,6}$, \\ Shengfeng Chen ${ }^{2}$, Qi Wang ${ }^{1,4}$, Yi Wang $^{3^{*}}$, Jiang Peng ${ }^{2^{*}}$ and Jinshu Tang ${ }^{1 *}$
}

\begin{abstract}
Various immune cells and cytokines are present in the aftermath of peripheral nerve injuries (PNI), and coordination of the local inflammatory response is of great significance for the recovery of PNI. Mesenchymal stem cells (MSCs) exhibit immunosuppressive and anti-inflammatory abilities which can accelerate tissue regeneration and attenuate inflammation, but the role of MSCs in the regulation of the local inflammatory microenvironment after PNI has not been widely studied. Here, we summarize the known interactions between MSCs, immune cells, and inflammatory cytokines following PNI with a focus on the immunosuppressive role of MSCs. We also discuss the immunomodulatory potential of MSC-derived extracellular vesicles as a new cell-free treatment for PNI.
\end{abstract}

Keywords: Mesenchymal stem cells (MSCs), Immunomodulation, Peripheral nerve injury, Review

\section{Background}

Peripheral nerve injury (PNI) refers to varying degrees of trauma to peripheral nerve stems or branches. PNI accounts for $1.5-4.0 \%$ of global trauma cases annually [1] and is one of the most challenging health issues at present. Nerve regeneration is a complicated cellular process involving inflammation, neurotrophic factors, neurotransmitters, adhesion, the formation of axons and growth cones, and the survival of neurons [2]. PNI triggers a series of immunoregulatory reactions in the cellular microenvironment, involving changes of immune cells and related immunoregulatory factors. Immunomodulatory factors currently known include interleukin-1

\footnotetext{
*Correspondence: wangyi1@301hospital.com.cn; pengjiang301@126.com; drtang304@126.com

${ }^{1}$ The Fourth Medical Center of Chinese PLA General Hospital, Beijing 100853, People's Republic of China

${ }^{2}$ Institute of Orthopedics, Chinese PLA General Hospital, Beijing Key Lab of Regenerative Medicine in Orthopedics, Key Laboratory of Musculoskeletal Trauma \& War Injuries PLA, Beijing 100853, People's Republic of China

${ }^{3}$ Department of Stomatology, First Medical Center, Chinese PLA General Hospital, Beijing 100853, People's Republic of China

Full list of author information is available at the end of the article
}

(IL-1 $\alpha$, IL-1 $\beta)$, IL-2, IL-4, IL-6, IL-10, IL-12, IL-13, IL-17, IL-6 [3, 4], tumor necrosis factor-a (TNF- $\alpha)$, indoleamine-2, 3-dioxygenase (IDO), interferon- $\gamma$ (IFN- $\gamma$ ), transforming growth factor-betal (TGF- $\beta 1$ ), heme oxygenase-1 (HO-1), hepatocyte growth factor (HGF), nitricoxide (NO), human leucocyte antigen-G5 (HLA-G5) and prostaglandin E2 (PGE2) [5, 6].

Amongst other techniques, autologous nerve grafting, nerve conduit synthesis [7], stem cell transplantation [8], and exosome extraction [9] are currently more popular treatments for PNI. For peripheral nerve damage of more than $3 \mathrm{~cm}$ in length, autologous nerve grafting is considered the gold standard treatment [10]. Stem cell transplantation is a novel method capable of regulating the inflammatory response which may accelerate the transition from destructive to restorative inflammatory microenvironment [11] and has been confirmed to promote the regeneration of peripheral and central nerves [12]. Mesenchymal stem cells (MSCs) can produce a variety of immunoregulatory factors modulating the immune function of autologous and allogeneic immune cells as well as innate (including natural killer (NK) cells[13], neutrophils, macrophages, mast cells, 
and dendritic cells (DCs)) and acquired immune cells (including T cells and B cells) [14] (Fig. 1). MSCs exert their immunomodulatory role via two distinct mechanisms: secretion of cytokines, including IDO (human) or NO (mouse), PGE2, IL-4, IL-10, IL-12, and IFN- $\gamma$, and TNF- $\alpha$, in a paracrine manner, and direct contact between cells [15]. The most important role of human MSCs (hMSCs) following injury is their secretion of bioactive molecules such as cytokines, chemokines, and growth factors, rather than their differentiation ability [16] and there are now several studies that have shown that many of the beneficial effects attributed to stem cell therapy may be mediated via paracrine mechanisms [17]. However, the immunomodulatory effects exerted by MSCs after PNI are not entirely clear. In this review, we discuss the changes occurring in the inflammatory microenvironment after treatment of PNI with MSCs and MSC-derived exosomes (exos), as well as the immunomodulatory effects exerted by different immune cells and inflammatory factors.

\section{MSCs exert immunomodulatory effects by modulating cytokine expression} MSCs downregulate the expression of pro-inflammatory factors

It has been reported that MSCs can suppress the expression of a variety of inflammatory cytokines in different diseases, such as IL-17, IL-1 $\beta$, IL-6, IL-3, IL-8, IL-21, IL-22, IL-7, IFN- $\gamma$, TNF- $\alpha$, and IL-12, among others. After PNI, pro-inflammatory factors such as IL-1, IL-2, IL-6, and TNF- $\alpha$ are expressed during the first stage of Wallerian degeneration, which promotes the recruitment of macrophages within 2-3 days [18]. However, the inflammatory response exerts different functions at different timepoints following injury. Results by Mietto et al. suggested that in the early stage of injury, proinflammatory cytokines such as IL- $1 \beta$ and TNF- $\alpha$ are predominantly secreted by de-differentiated Schwann cells (SCs) after losing contact with axons, which then recruit macrophages to the site of injury [19]. Chen et al. found that pro-inflammatory cytokines surrounding the

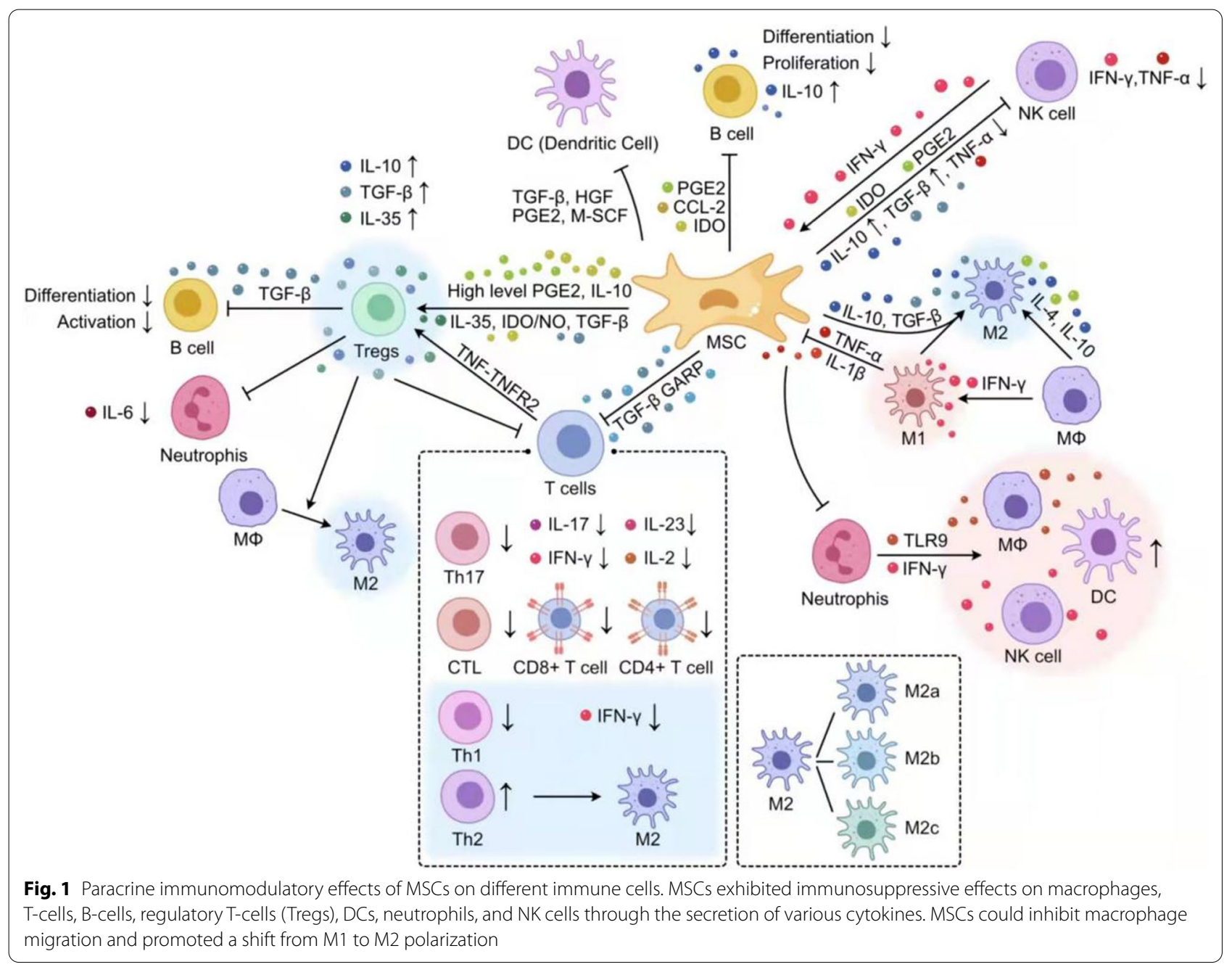


injured peripheral nerve were significantly increased in the lymph nodes (LN), creating a pro-inflammatory environment, thereby leading to autoimmune reactions against peripheral nerve antigens [20]. MSCs exhibit strong plasticity and can switch from the pro-inflammatory "MSC1" type to the anti-inflammatory "MSC2" type. Following stimulation with pro-inflammatory factors such as IL- $1 \alpha$, TNF- $\alpha$, and IFN- $\gamma$, or after toll like receptor 3 (TLR3) activation, resting-state MSCs are polarized to the anti-inflammatory MSC2 type, producing large amounts of NO/IDO and other immunoregulatory factors and chemokines which play an immunosuppressive role by inhibiting the function of effector $\mathrm{T}$ cells and inducing the production of regulatory $\mathrm{T}$ cells (Treg cells) [14]. Moreover, Omi [21] et al. reported that DPSC transplantation can significantly reduce the expression of proinflammatory cytokines IL-1 $\beta$ and TNF- $\alpha$ and increase M2 polarization and recruitment under the inflammatory condition of diabetic peripheral nerves. In addition, among the numerous proinflammatory factors affected by MSCs after PNI, IFN- $\gamma$, IL-1, TNF- $\alpha$, IL-6, and IL-17 have been widely studied in peripheral nerve regeneration. Below is some simple summary of them.

\section{MSCs suppress the expression of IFN- $\gamma$}

Previous studies have shown that low levels of IFN- $\gamma$ can accelerate the spread of stem cells. SCs exhibited higher levels of proliferation and expression of elevated GDNF levels when cultured in a medium containing IFN- $\gamma$ [22]. Several studies have also shown that MSCs can suppress the expression of IFN- $\gamma$. For instance, Aggarwal et al. found that co-culture of different immune cells with hMSCs resulted in an inhibition of IFN- $\gamma$ expression and an increase in IL-4 secretion [23], increased the transition of pro-inflammatory Th1 cells to anti-inflammatory Th2 cells, and facilitated the generation of CD25 + and $\mathrm{CD} 4+$ regulatory $\mathrm{T}$ cells. Other studies have proven that IFN- $\gamma$ can enhance the immunomodulatory capacity of MSCs. For instance, Kim [24] et al. reported that IFN- $\gamma$-primed MSCs could not only upregulate the gene expression of chemotactic factors cysteine-X-cysteine chemokine ligand 9 (CXCL9), CXCL10, CC-chemokine ligand 8 (CCL8), which may possess a significant potential to recruit leukocytes but also highly promote the IDO expression through the JAK-STAT1 signaling pathway, thereby contributing to the inhibition of T-cells mediated by MSCs. Domenis et al. suggested that the proinflammatory cytokines IFN- $\gamma /$ TNF- $\alpha$ may improve the immunomodulatory and anti-inflammatory potential of exosomes released by adipose-derived mesenchymal stem cells (AD-MSCs) promote macrophage polarization toward the M2 type, and the authors also speculated that the immunomodulatory properties of AD-MSCs-derived exosomes may be a result of the inflammatory microenvironment [25].

\section{MSCs decrease the expression of IL-1}

There are two types of IL-1, IL- $1 \alpha$, IL- $1 \beta$. The basic function of IL- $1 \alpha$ is to induce the generation of IL- 6 and granulocyte-macrophage colony-stimulating factor (GM-CSF) in fibroblasts in situ, which can be detected within 2 to $5 \mathrm{~h}$ after an injury [26]. IL-1 $\beta$ may promote nerve regeneration via the nuclear factor- $k B$ (NF- $k B$ ) signaling pathway [27]. Previous studies suggested that there are low levels of IL- $1 \beta$ one hour after injury, but one-day post-injury-before macrophage recruitmentthe secretion of IL- $1 \beta$ peaks [28], 6 and $24 \mathrm{~h}$ after injury, the expression levels of IL-1 $\beta$ is 2 times and 10 times higher than in the control groups $[29,30]$. High levels of IL-1 $\beta$ are maintained for several days [27], gradually decreasing and finally returning to the baseline levels around 14 days after PNI. MSCs can reduce IL-1 expression: for instance, a study by Chen et al. reported that bone-marrow-derived MSCs significantly reduced the expression of IL-1 $\beta$ in mice following spinal cord injury (SCI) [31].

\section{MSCs downregulate the secretion of TNF- $a$}

TNF can be regenerated by monocytes, macrophages, and other immune cells such as DCs, B cells, activated NK cells, and T cells [32]. Similar to IL-1 $\beta$, TNF- $\alpha$ reaches its secretory peak one day after PNI [28] In addition, TNF can promote nerve regeneration by controlling the number of neutrophils and IL-1 $\beta$ expression [33]. The proinflammatory microenvironment mediated by TNF- $\alpha$ plays a significant role in the immunoregulatory function of MSCs. For example, pre-treatment of MSCs with TNF- $\alpha$ promotes the secretion of anti-inflammatory cytokines including IL-10 and TGF- $\beta$, enhancing immunosuppression and inducing anti-inflammatory Tregs [34]. Inhibition of the TNF- $\alpha$-TNFR2 signaling pathway in MSCs caused a decreased IL-10 and TGF- $\beta$ secretion, while increasing secretion of TNF- $\alpha$, INF- $\gamma$, IL-2, and IL-17 by effector T cells (Teffs) [35]. The protective functions mediated via the TNF $\alpha$-TNFR2 pathway result in cell proliferation and survival [36]. However, TNF- $\alpha$ has also been shown to inhibit the function of MSCs in nerve repair by activating the Wnt signaling pathway under certain circumstances [37].

\section{MSCs reduce the expression of IL- 6}

IL-6 is a pluripotent cytokine that not only can accelerate the proliferation and activation of effector $\mathrm{T}$ cells through immunostimulation, but also regulate Treg cells through immunosuppression [26, 38]. IL-6 is not detected in intact nerves, but recent studies have 
revealed that the cytokine IL- 6 is produced by macrophages and fibroblasts in the injured peripheral nerve [39], and its expression is regulated by TNF- $\alpha$. After sciatic nerve injury, macrophage-derived IL-6 levels are increased within $2 \mathrm{~h}$. In SCs, its expression is increased within $3 \mathrm{~h}$ of injury and maintained for at least 21 days. Co-culturing the facial nerve with BMSCs in vitro, Ge et al. and found that BMSCs secrete high levels of IL-6 to regulate the balance of CD4 $+\mathrm{T}$ cell subsets, to achieve future treatment of facial nerve injury [40]. Baez-Jurado demonstrated that astrocytes co-cultured with the conditioned medium from AD-MSCs reduced the expression levels of IL-6, TNF- $\alpha$, and GM-CSF and increased the expression levels of neuroprotective cytokines [41] to regulate brain inflammation. Moreover, GM-CSF has been shown to suppress inflammation and potentially improve the microenvironment toward promoting the clearance of myelin debris by increasing the expression of galectin-3 on SCs [42] and enabling axonal regeneration [43]. GM-CSF plays a key role in the development and maturation of DCs as well as in the proliferation and activation of T-cells [44].

\section{MSCs downregulate the expression of IL-17}

IL-17 is produced by activated CD4 $+\mathrm{T}$ cells and increases the production of proinflammatory factors and neutrophil mobilizing cytokines, such as TNF- $\alpha$, IL-1 $\beta$, and G-CSF [45]. IL-17 has been shown to play a crucial role in the regulation of inflammatory responses in autoimmune diseases. IL-17 can promote the release of inflammatory factors TNF- $\alpha$, IL-6, and IFN- $\gamma$ [46]. IL-15 and IL-23, derived from dendritic cells and macrophages, respectively, are the most significant regulatory factors of the expression of IL-17A [47]. The expression of these two factors increases on the first day after sciatic nerve injury, and their peaks precede the peak expression of IL-17A, suggesting that they act as inducers of IL-17A after PNI. The expression of IL-17A peaks on day 7 after PNI [48]. The infiltration of inflammatory cells and levels of pro-inflammatory cytokines surrounding the injury site were significantly reduced in IL-17-knockout mice compared to controls after partial sciatic nerve ligation was significantly reduced, while the expression of anti-inflammatory cytokines IL-10, IL-13, and enkephalin were increased. Yining et al. found that BMSCs can promote the proliferation and differentiation of Th17 cells which secrete IL-17 and in turn promote BMSC secretion of PGE2, while high levels of PGE2 negatively regulate IL-17 secretion by Th17 cells [40].
MSCs exert immunomodulatory effects after PNI by increasing the expression of anti-inflammatory factors Following SCI, the anti-inflammatory factors IL-10 and TGF- $\beta$ can be detected after PNI following macrophage recruitment [18], which can reduce the inflammatory response and promote neural tissue regeneration [49]. The release of IL- 4 and IL-13 by Th 2 can accelerate the activation of M2 macrophages, promote the expression of anti-inflammatory cytokines IL-10 and TGF- $\beta$, and up-regulate the expression of extracellular matrix protein, growth factor, and arginase [50]. Several studies have revealed that MSCs can promote the expression of anti-inflammatory factors. For instance, Aline et al. found that mice treated with Wharton's jellyderived MSCs (WJ-MSCs) exhibited increased levels of IL-4, IL-10, IL-35, and TGF- $\beta$ [51]. The authors concluded hWJ-MSCs may regulate immune cell function via secretion of high levels of TGF- $\beta$ and IL-35, to adjust the inflammatory microenvironment to promote the recovery of the sciatic nerve. In this review, we have focused on describing the main representative anti-inflammatory factors IL-10 and IL-4. However, it should be noted that IL-4 and IL-10 are not the sole representatives after PNI.

\section{MSCs increase the expression of IL-10}

IL-10 is a type of pro-regenerative cytokine. Increased expression of IL-10 is associated with wound healing, tissue remodeling, and myelin regeneration [51]. It has been suggested that the production and secretion of IL-10 are induced by fibroblasts within $5 \mathrm{~h}$ after injury, but the low levels of IL-10 produced by fibroblasts are insufficient to aid substantial repair. To overcome this, recruited macrophages, who are the key cell type expressing IL-10, produce and secrete IL-10. mRNA levels of IL-10 increase from the first day after the injury, increase significantly on day 4, peak on day 7 , and are maintained at high levels until day $14[18,53]$. Protein expression of IL-10 gradually increases in the first two weeks after injury [53]. IL-10 can limit the expression of proinflammatory cytokines IL-1, TNF- $\alpha$, and IL-6, as well as Th1-derived cytokines such as IL-2 and IFN- $\gamma$. Moreover, IL-10 regulates the differentiation and proliferation of macrophages, $\mathrm{T}$ cells, and B cells [26]. Ydens et al. found that sciatic nerve transection injury can induce an immunosuppressive response, increase levels of IL-10, and provide a microenvironment conducive to macrophage polarization to M2 type [54]. Additionally, Obermajer et al. found that both IL-10 and HLA-G5 are essential for MSCmediated immunosuppression, and the two molecules 
exert synergistic effects[55], and can also enhance the anti-inflammatory potential of MSCs. Cui et al. showed that BMSCs stimulated with IL-10 inhibit the expression of TNF- $\alpha$ and IL-1 $\beta$ [56].

\section{MSCs promote the expression of IL-4}

It is becoming increasingly clear that IL-4 is an important immunomodulatory cytokine. It can not only recruit more macrophages but also promote macrophage M2 type polarization, which has the potential to promote peripheral nerve regeneration [57]. MSCs expressing IL-4 can induce macrophage M2 polarization [11] and further promote the expression of IL-4. In addition, M2 macrophages induced by IL- 4 or the other anti-inflammatory cytokines can suppress anti-inflammatory responses and promote angiogenesis and axonal regeneration [58]. Ullah et al. found that the expression IL- 4 and TGF- $\beta$ were reduced at 2 weeks after sciatic nerve injury when treated with dental pulp-derived stem cells (DPSCs), whose levels gradually increased at 8 and 12 weeks after injury [59]. Moreover, Yagura et al. demonstrated that transplanted MSCs could induce euronal cells to secrete CCL 5 binding to the macrophage surface, which induced high levels of IL-4 expression to promote macrophage polarization to type M2 [60].

\section{Immunomodulatory effects of MSCs on immune cells in PNI}

MSCs promote macrophage polarization toward M2 type

During acute inflammation, macrophages can amplify the inflammatory response and recruit additional immune cells via phagocytosis of invading microorganisms [61]. Two to three days after an injury, blood-derived macrophages in the distal nerve begin to accumulate and reach their numbers peak around 7-14d after injury. Macrophages infiltrating the injured nerve express and produce a great number of cytokines such as CCL2 and TNF- $\alpha$, IL- $1 \alpha$, and IL- $1 \beta$, to promote the further recruitment of monocytes or macrophages [28, 62]. Both cellto-cell contact and secreted factors are essential for the modulation of macrophages by MSCs. It has been confirmed that MSCs can secrete a variety of growth factors, chemokines, as well as other signaling molecules to regulate macrophage maturation, polarization, and proliferation [63, 64]. For instance, Zhong et al. reported that BMSCs can secrete GDNF that converts microglial destructive M1-phenotype into regenerative M2-phenotype for the suppression of neuroinflammation, possibly through the inhibition of NF- $\mathrm{kB}$ signaling pathway and the promotion of the PI3K/AKT signaling pathway [65]. Additionally, several studies have shown that MSCs can influence M1/M2 polarization. For example, by co-culturing ADMSCs with human peripheral blood monocytes (PBMCs) to explore the effects of MSCinduced macrophages (iMФ) on inflammation modulation, Heo et al. found that macrophages highly expressed M2 type markers, indicating that secreted factors derived from MSCs promoted M2 polarization [66]. Using coculture of bone marrow-derived macrophages with MSCs, Xu et al. found that MSCs significantly promoted macrophage polarization from M1 to M2 [67]. MSCs are thought to modulate activation and polarization of macrophages via four molecular pathways which downregulate the release of pro-inflammatory cytokines and accelerate nerve repair and regeneration, including PGE2, tumor-necrosis-factor-inducible gene 6 protein (TSG-6), progesterone receptor (PR), and glucocorticoid receptors (GR). Chen et al. found that exosomes derived from human umbilical cord-derived MSCs (hUC-MSCs) could modulate macrophages towards M2 polarization [68]. Peruzzaro et al. showed that MSCs can change the ratio of classical to M2 macrophage/microglia phenotypes following traumatic brain injuries (TBI), increasing the proportion of M2 cells around the injury site [64]. Moreover, macrophages can also influence MSCs. For example, Ma et al. found that macrophages can inhibit the proliferation and differentiation of ADSCs by secreting pro-inflammatory cytokines, mainly TNF- $\alpha$ and IL-1 $\beta$ [69]. Several studies have shown that NF- $k B$ is a crucial regulator of inflammatory signaling and molecular determinant of macrophage phenotype by inducing inflammatory mediators such as IL-1 $\beta$, IL-6, TNF, IL-12, CXCL-8, and cyclooxygenase (COX) [70]. John et al. proposed that the inhibition of NF-kB signaling macrophages could activate neutrophils as a result of the reduced release of proinflammatory cytokines [71].

In conclusion, MSCs can decrease the infiltration of M1 macrophages and promote macrophage polarization from M1 to M2 type, thereby reducing pro-inflammatory and increasing anti-inflammatory cytokines.

\section{$M S C s$ reduce the expression of $T$ lymphocytes}

Similar to macrophages, $\mathrm{T}$ lymphocytes are essential for peripheral nerve regeneration. $T$ cells can regulate nerve regeneration through a variety of mechanisms, including the secretion of cytokines, release of growth factors, or direct interaction with cells [72]. MSCs can suppress the proliferation of activated $\mathrm{T}$ lymphocytes in a dose-dependent manner, which is thought to be mediated by the expression of IDO and COX2 [73]. MSCs have been proven to exhibit immunomodulatory effects on $\mathrm{T}$ cells in vitro. For instance, MSC-conditioned medium promotes $\mathrm{T}$-cell production of antiinflammatory cytokines TGF- $\beta$, IL- 4, IL- $10, \mathrm{NO}$, and IDO [74]. Heo et al. found that iMФ strongly inhibited T lymphocytes [66]. Furthermore, MSC also has been 
shown to exert immunosuppressive functions on $\mathrm{T}$ cells in vivo. Siniscalco et al. found that hMSCs delivered systemically via the tail vein decrease secretion levels of IL- $1 \beta$ and IL-17 and increase expression levels of IL-10 and the CD206 macrophage marker in a mouse model of neuropathic pain, thus the authors concluded that $\mathrm{T}$ lymphocytes are associated with the production of proinflammatory cytokines IL-17 and IL-1 $\beta$ [75]. Alternatively, although $\mathrm{T}$ cells do not produce IL-4, they have been shown to recruit eosinophils that can express IL-4, both in vivo and in vitro, to promote nerve regeneration [76]. MSCs can inhibit T cell proliferation by promoting the multiplication of Tregs [77], and suppressing conventional $\mathrm{T}$ cells, converting them to Tregs [78]. Moreover, umbilical cord blood-derived MSCs pretreated with IFN- $\gamma$ could suppress the function of mature dendritic cells, thus stimulating T-lymphocyte proliferation after direct contact [79].

In summary, MSCs could reduce the inflammatory response by inhibiting $\mathrm{T}$-cells proliferation and activation.

\section{MSCs promote the proliferation and differentiation of Treg cells}

MSCs transplantation promotes the expansion of Tregs in injured tissues [80]. Maintaining the balance between Tregs and inflammatory cytokines is an important immunoregulatory role of MSCs. For instance, several studies found that IL- 6 combined with TGF- $\beta$ can induce Th17 cell differentiation, while TGF- $\beta$ induces differentiation of Tregs [62]. Tregs produce proinflammatory factors under certain conditions, but generally produce anti-inflammatory cytokines such as IL-10, TGF- $\beta$, and IL-35, which participate in the immunosuppressive function of Tregs, promoting functional recovery of injured peripheral nerve $[81,82]$. TNF can not only reduce the suppressive function of Treg cells, but also promote their proliferation under certain conditions in vitro [83]. Aline et al. found that hWJ-MSC promotes higher expression levels of anti-inflammatory cytokines IL-35 and TGF- $\beta$ in Tregs when compared with that in fibroblasts [51]. In the treatment of PNI, an increased level of IL-35 can induce Tregs differentiation [84]. In addition interacting with cytokines, Tregs can induce neutrophil apoptosis, promote the expression of TGF- $\beta 1$ and IL-10, and inhibit neutrophil production of IL-6 to create anti-inflammatory conditions that favor tissue repair. Additionally, IL-10 also can counteract Tregs [85]. Tregs contribute to the inhibition of monocyte secretion of inflammatory factors that promote macrophage polarization toward the M2 phenotype.
Therefore, MSCs can induce the generation of Tregs in the inflammatory microenvironment so as to inhibit the immune response and attenuate the resultant inflammation.

\section{MSCs inhibit the activation of NK cells}

Several studies have shown that MSCs may inhibit NK cell proliferation and cytotoxic activity [86], including suppression of proliferation of resting NK cells induced by IL-2, the secretion of pro-inflammatory factors such as TNF- $\alpha$ and IFN- $\gamma$, and their killing capacity on target cells. The inhibitory effect of MSCs on NK cells is dosedependent and a significant inhibitory effect can only be achieved by maintaining a high MSC/NK cells [87]. Noone et al. proposed that hUCMSCs can inhibit NK cell activation via secretion of PGE2 [13]. Aggarwal et al. found a statistically significant reduction in IFN- $\gamma$ production after co-culture of hMSCs with IL-2-stimulated NK cells [23]. Moreover, Qiang et al. found that co-culture of NK cells with DMSCs resulted in downregulation of perforin, IFN- $\gamma$, and TNF- $\alpha$, and upregulation of IL-4 and IL-10 in NK cells [88]. In addition, the interaction between M2 macrophages induced by MSCs and NK cells can inhibit the expression of proteins related to NK cell activation, such as NKp44, CD25, CD69, and IFN- $\gamma$. Other studies have shown that IFN- $\gamma$ can enhance the immunomodulatory ability of MSCs. Considering the development time frame of adaptive immunity, if cell therapy is allowed to occur, NK cells may be the source of IFN- $\gamma$ of MSCs in vivo [86].

\section{The immunomodulatory effects of MSCs combined with nerve conduits in the treatment of PNI}

Some studies have suggested that stem cell transplantation combined with different nerve conduits may represent a promising strategy for the treatment of PNIs. Acellular nerve allografts (ANAs) are the most widely used biomaterials for nerve repair in the clinic. Recent studies have revealed that in the use of ANAs for bridging the nerve defects, $T$ cells regulate the secretion of inflammatory cytokines within ANAs concerning the length of the ANA. For instance, long ANAs $(4 \mathrm{~cm})$ trigger a lower accumulation of $\mathrm{T}$ cells and cytokine levels of IFN- $\gamma$, IL-2, IL-4, and IL-13 [21]. Deng et al. found that T cells can regulate IL-4 by affecting eosinophils levels in ANAs [76]. ANAs combined with MSCs have been suggested to be effective for the treatment of PNI, and the regulation of the inflammatory microenvironment surrounding the injured nerve is currently being explored. For instance, Fan [89] et al. demonstrated that BMSCs combined with xenogeneic acellular nerve grafts (xANGs) could better promote nerve regeneration, possibly by reducing 
the release of pro-inflammatory factors IL-2, IFN- $\gamma$, and TNF- $\alpha$ and increasing the secretion of IL-10 in lymphocyte supernatants and serum when compared with those in the xANG group $(5 \mathrm{~mm})$. Yue et al used a $15 \mathrm{~mm}$ artificial nerve composed of epidermal neural crest stems cells (EPI-NCSCs), extracellular matrix (ECM), and polylactic co glycolic acid (PLGA) to treat peripheral nerve injury and found that after bridging with EPI-NCSCs, the expression of anti-inflammatory cytokines IL- 4 and IL-13 increased, while the expression of pro-inflammatory cytokines IL- 6 and TNF- $\alpha$ decreased [90]. Seven days after transplantation, M2 macrophages increased, while M1 macrophages decreased. Moreover, the number of SCs promoting myelination increased significantly 21 days after transplantation, while the number of activated fibroblasts decreased, and the structural and functional recovery of those animals treated with EPI-NCSCs was significantly better than in the DMEM blank control group. Therefore, the authors concluded that the combination of ANA with MSCs provides an inflammatory microenvironment suitable for sciatic nerve repair.

\section{Immunomodulatory effects of MSC-derived extracellular vesicles in PNI}

A large body of research suggests that the majority of MSC-derived immunosuppressive effects are attributed to the immunoregulatory properties of the MSC-derived secretome, which is composed of a soluble component and encapsulated extracellular vesicles (EVs): apoptotic bodies, exosomes (exos), and microvesicles [91]. Due to their low immunogenicity, EVs derived from MSC (MSC-EVs) are considered as an appealing cell-free therapy. Recent studies have revealed MSC-EVs may exert anti-inflammatory functions that are similar to MSCs, and achieve their anti-inflammatory effects by reducing levels of inflammatory cytokines and enhancing anti-inflammatory responses [92]. Ma et al. found that hUCMSC-EVs can inhibit the expression of pro-inflammatory cytokines IL- 6 and IL-1 $\beta$ and up-regulate IL-10 expression to rebalance the inflammatory responses in a rat sciatic nerve injury model [93]. Sheng [94] et al. reported that rats treated with MSCs-EV and miRNA22-loaded MSCs-EV (EV-miRNA-22) exhibited attenuated levels of pro-inflammatory factors TNF- $\alpha$, IL-1 $\beta$, and IL-18, and both showed a good ability to promote nerve regeneration, albeit the effect of EV-miRNA-22 was better than that of the EV group. On the other hand, miRNA-22 could inhibit the production and release of inflammatory responses. In addition, MSC-EVs can also exert immunomodulatory effects by modulating immune cells. For example, MSC-derived small extracellular vesicles (sEVs) can enhance IL-10 and TGF- $\beta$ expression by inhibiting $\mathrm{T}$ lymphocyte proliferation and promoting their apoptosis, while decreasing the proportion of Th17 cells and increasing Treg cells in the spleen, leading to a decrease of IL-17 levels in serum [95]. Extracellular vesicles derived from CD73 modified hUC-MSCs can promote M2 macrophage polarization while decreasing the expression of pro-inflammatory factors TNF- $\alpha$, IL- $1 \beta$, and IL-6, and increasing the expression of anti-inflammatory factors IL-4 and IL-10 [96].

The immunomodulatory activity of MSC-Derived EVs may be regulated by Hypoxia-inducible factor 1-alpha (HIF-1 $\alpha$ ) [97]. Over-expression of HIF-1 $\alpha$ in MSCs can enhance their immunosuppressive ability in different immune cell populations including DCs, monocytes, and NK cells [98]. Table 1 demonstrates the immunomodulatory effects of MSC-EVs for the attenuation of inflammatory diseases $[80,95,99-128]$ (Table 1 ).

\section{Conclusion and deficiency}

MSCs are multipotent stem cells with multiple biological potentials and may represent an ideal option for cell therapy applications due to their regenerative and immunoregulatory functions [129]. The use of MSCs with innate mechanistic features to mediate the local inflammatory response following PNI would both reduce loss of muscle mass and shift the microenvironment towards a pro-regenerative rather than profibrotic phenotype [130]. Animal studies with intravenous reinfusion transplantation or local tissue injection of MSCs have found that these cells can quickly migrate to injury sites and localize to sites of information where they promote antiinflammatory and immune regulatory effects [131-133]. There is a correlation between higher MSCs survival and reduced levels of pro-inflammatory cytokines as well as a transformation in macrophages from M1 to M2 [134]. However, currently studies investigating the immunoregulatory mechanisms of MSCs for the treatment of PNI are not comprehensive enough, and the functions played by different immune cells and cytokines remain to be studied. Moreover, the various pathways involved in the mediation of MSC-derived benefits remain to be explored. Stem cell transplantation studies are at this point predominantly in pre-clinical stages, with several issues needing to be addressed. Although the effectiveness of MSCs/MSCs-EVs for the treatment of PNI has been demonstrated many times in animal studies, there are still few studies highlighting the exact therapeutic mechanisms, in particular relating to the immunoregulatory mechanisms exerted by MSCs/MSCs-EVs. Further studies investigating the molecular mechanism underlying the beneficial effects of MSCs in the treatment of PNI will provide new strategies for disease therapy. 
Table 1 Immunomodulatory effects of MSC/MSC-EVs for the attenuation of inflammatory diseases

\begin{tabular}{|c|c|c|c|c|c|c|}
\hline Disease model & $\begin{array}{l}\text { Animal for In Vivo } \\
\text { study }\end{array}$ & MSC source & Effects on immune cells & $\begin{array}{l}\text { Effects on } \\
\text { cytokines }\end{array}$ & $\begin{array}{l}\text { Signaling } \\
\text { pathway/related } \\
\text { exosomal cargo }\end{array}$ & Ref. No \\
\hline Arthritis & In vitro & BMSCs,BMSCs-Exos & $\begin{array}{l}\text { CD8 or CD } 4 \text { T lymphocytes } \downarrow \text {, } \\
\text { B lymphocytes } \uparrow\end{array}$ & IFN- $\gamma, T N F-a \downarrow ; \mid L-10 \uparrow$ & - & [99] \\
\hline \multirow[t]{3}{*}{$\mathrm{IBD}$} & \multirow[t]{3}{*}{ Mouse } & OE-MSCs-Exos & $\begin{array}{l}\text { the differentiation of Th1 and } \\
\text { Th17 cells } \downarrow \text {, Treg cells } \uparrow\end{array}$ & $\begin{array}{l}\text { IL-17, IFN- } \gamma \downarrow ; \text { TGF- } \beta, \\
\text { IL-10个 }\end{array}$ & - & {$[100]$} \\
\hline & & hP-MSCs-EVs & - & $\begin{array}{l}\text { IL-10, TGF- } \beta \uparrow ; \text { TNF- } \\
\text { a, IL-1 } \beta, \text { IFN- } \gamma \text { and } \\
\text { IL-6 } \downarrow\end{array}$ & - & [101] \\
\hline & & MuSCs & $\begin{array}{l}\text { M2 } \\
\text { macrophages } \uparrow, \text { macrophages } \\
\text { infiltration } \downarrow\end{array}$ & $\mid \mathrm{L}-6, \mathrm{IL}-1 \beta \downarrow$ & - & [102] \\
\hline IUAs & Rat & $\begin{array}{l}\text { UC-MSC-derived } \\
\text { exosomes }\end{array}$ & M2 macrophage $\uparrow$ & $\begin{array}{l}\text { IL-1 } \beta, \| L-6 \text { and TNF- } \\
a \downarrow ; \mid L-10, T G F-\beta \uparrow\end{array}$ & - & [103] \\
\hline Liver disease & Mouse & hUC-MSCs & CD4 and CD8 T cells $\downarrow$ & $\mid F N-\gamma \downarrow$ & - & [104] \\
\hline ALI & Mouse & UC-MSCS & $\begin{array}{l}\text { M2 macrophage } \uparrow \\
\text { M1 macrophage } \downarrow\end{array}$ & $\begin{array}{l}\text { TNF- } \alpha, \| L-1 \beta \text { and } \\
\| L-6 \downarrow\end{array}$ & - & [105] \\
\hline \multirow[t]{2}{*}{ EAE } & \multirow[t]{2}{*}{ Mouse } & BMSCs & T cells $\downarrow$ & - & STAT1,STAT3,mTOR & {$[106]$} \\
\hline & & hUCMSC-EV & $\begin{array}{l}\text { the leukocyte } \\
\text { infiltration } \downarrow \text {,Tregs } \uparrow\end{array}$ & $\begin{array}{l}\text { IL-17a, TNF- } a \text {, and } \\
\text { IFN- } \downarrow \downarrow ;|L-4,| L-10 \uparrow\end{array}$ & - & [107] \\
\hline $\begin{array}{l}\text { Lung injury and } \\
\text { fibrosis }\end{array}$ & Mouse, monkeys & hESCs & - & $\begin{array}{l}\text { TNF- } a, \text { TGF- } \beta 1, \text { IL-6, } \\
\text { IL-1 } \beta, \text { GRO- } a, \mid \mathrm{IL}-1 a \text {, } \\
\text { IL-3 and IL- } 8 \downarrow\end{array}$ & - & [108] \\
\hline Wound healing & Mouse & BMSCs & M2 polarization $\uparrow$ & IL-10个;TNF-a $\downarrow$ & $\operatorname{miR}-223$ & [109] \\
\hline Skin defect & Mouse & hBMSCs & M2 macrophages $\uparrow$ & - & miR-150-5p & [110] \\
\hline IVD & Bovine & hBMSCs & - & $\begin{array}{l}\text { IL-6, IL-8 and TNF- } a \\
\downarrow\end{array}$ & - & [111] \\
\hline Renal injury & Mouse & BMSC-exos & $\begin{array}{l}\text { infiltration of of mac- } \\
\text { rophages } \downarrow\end{array}$ & $\begin{array}{l}\text { TNF- } \alpha, I L-6 \text { and } \\
I L-1 \beta \downarrow\end{array}$ & CCL2 & [112] \\
\hline Renal Diseases & Rat & hUCMSC-Ex & - & $\begin{array}{l}\text { TNF- } a, I L-6 \text { and } \\
\| L-1 \beta \downarrow\end{array}$ & mTOR & [113] \\
\hline cGVHD & Mouse & BMSC-exos & $\begin{array}{l}\text { Th17 cells, CD4 + T cells } \downarrow \text {, } \\
\text { Tregs } \uparrow\end{array}$ & 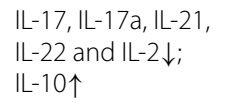 & - & [114] \\
\hline aGVHD & Mouse & BMSC-exos & $\begin{array}{l}\text { CD8aDCs, CD11b cDCs } \uparrow \text {; CD8, } \\
\text { CD3CD4 T cells } \downarrow\end{array}$ & $\begin{array}{l}\text { IL-2, TNF- } \alpha \text { and IFN- } \\
\gamma \downarrow ; \mathrm{IL}-10 \uparrow\end{array}$ & - & [115] \\
\hline $\begin{array}{l}\text { Heart allograft } \\
\text { rejection }\end{array}$ & Rat & IDO-BMSCs & Tregs $\uparrow, D C \downarrow$ & $\begin{array}{l}\text { IL-10, TGF- } \beta 1, \text { TGF- } \\
\beta 2 \text { and TGF- } \beta 3 \uparrow ; \\
\text { IL-2, IFN- } \gamma \downarrow\end{array}$ & - & [116] \\
\hline \multirow[t]{3}{*}{$\mathrm{ClA}$} & Rat & hUCMSCs & $\begin{array}{l}\text { T lymphocytes (proliferation } \downarrow \text {, } \\
\text { apoptosis } \uparrow \text { ), Th17 cell } \downarrow \text {, } \\
\text { Tregs } \uparrow\end{array}$ & IL-17, TGF- $\beta \downarrow$ & $\begin{array}{l}\text { RORyt mRNA,Foxp3 } \\
\text { mRNA }\end{array}$ & [117] \\
\hline & Mouse & hADMSCs & $\begin{array}{l}\text { Tregs } \uparrow \text {, the proliferation of } T \\
\text { cells } \downarrow\end{array}$ & 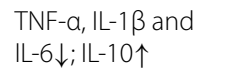 & - & {$[80]$} \\
\hline & Rat & hUCMSC-sEVs & $\begin{array}{l}\text { Th17 cell } \downarrow, T \text { lymphocyte } \\
\text { proliferation } \downarrow \text {, Tregs } \uparrow\end{array}$ & $\begin{array}{l}\mathbb{I L}-17 \downarrow ; i L-10, T G F-\beta \\
\uparrow\end{array}$ & - & [95] \\
\hline $\mathrm{PNI}$ & $\begin{array}{l}\text { Rat(MRI, LPS and } \\
\text { FK506) }\end{array}$ & GFP-BMSCs & M1,TLR4 $\downarrow$ & 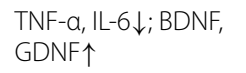 & - & [118] \\
\hline PSNL & $\operatorname{Rat(LPS)}$ & BMSCs & - & IL-1 $\beta$, TNF- $a \downarrow$ & - & [119] \\
\hline $\mathrm{CCl}$ & Rat(PMF) & ADMSCs & - & IL-6, IL-1 $\beta \downarrow ; \mid I L-10 \uparrow$ & - & [120] \\
\hline Diabetic & Rat & DPSCs & $\begin{array}{l}\text { CD206 } \uparrow, C D 68-p o s i t i v e \\
\text { monocytes/macrophages } \downarrow\end{array}$ & $\begin{array}{l}\text { TNF- } a, \| L-1 \beta \downarrow ; \\
\text { IL-10个 }\end{array}$ & - & [121] \\
\hline $\mathrm{CCl}$ and $\mathrm{SNI}$ & Mouse(TGF- $\beta 1)$ & BMSCS & - & $\begin{array}{l}\|-1 \beta,\| L-6 \text { and TNF- } \\
a \downarrow ; \text { TGF- } \beta 1 \uparrow\end{array}$ & - & [31] \\
\hline $\begin{array}{l}\text { Nerve injury- } \\
\text { induced pain }\end{array}$ & Rat & UCMSC-exos & - & TNF- $a, I L-1 \beta \downarrow$ & - & [122] \\
\hline Dysphagia & Rat & hDPSCs & M2 macrophages $\uparrow$ & iNOS, IL-1 $\beta \downarrow$ & - & [123] \\
\hline
\end{tabular}


Table 1 (continued)

\begin{tabular}{|c|c|c|c|c|c|c|}
\hline Disease model & $\begin{array}{l}\text { Animal for In Vivo } \\
\text { study }\end{array}$ & MSC source & Effects on immune cells & $\begin{array}{l}\text { Effects on } \\
\text { cytokines }\end{array}$ & $\begin{array}{l}\text { Signaling } \\
\text { pathway/related } \\
\text { exosomal cargo }\end{array}$ & Ref. No \\
\hline $\mathrm{TB} \mid$ & Rat & MSCs & $\begin{array}{l}\text { M1 macrophage } \downarrow \text {, M2 mac- } \\
\text { rophages } \uparrow\end{array}$ & 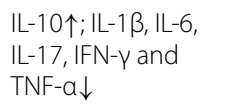 & NF-KB & [124] \\
\hline DAH & Mouse & hUCMSC-EX & $\begin{array}{l}\text { M1 macrophage } \downarrow \text {, M2 mac- } \\
\text { rophages } \uparrow\end{array}$ & $\begin{array}{l}\text { IL-6, TNF- } a \downarrow ; \text {; LL-10, } \\
\text { TGF- } \beta \uparrow\end{array}$ & - & {$[125]$} \\
\hline $\begin{array}{l}\text { Skeletal muscle } \\
\text { contusion }\end{array}$ & Mouse and in vitro & hBMSC-exos & $\begin{array}{l}\text { M1 macrophages } \downarrow, \mathrm{M} 2 \\
\text { macrophages } \uparrow\end{array}$ & $\begin{array}{l}\text { IL-6, TNF- }-\alpha ; \\
\text { IL-10,TGF- } \beta \uparrow\end{array}$ & - & [126] \\
\hline $\mathrm{SCl}$ & Mouse & hUCMSCs & M2 macrophages $\uparrow$ & $\begin{array}{l}\text { IL-7, IFN- }- \text {, and TNF- } \\
a \downarrow ; \mid L-4, I L-13 \uparrow\end{array}$ & - & {$[127]$} \\
\hline PF & Mouse & hUCMSCs & Tregs $\uparrow$ & CXCL9, CXCL10个 & - & {$[128]$} \\
\hline
\end{tabular}

Effect of MSCs on cytokines and immune cells when treating different diseases. BMSCs: bone marrow-derived mesenchymal stem cells; OE-MSCs: Olfactory ecto-mesenchymal stem cells; IBD: inflammatory bowel disease; IUAs: intrauterine adhesions; UC-MSC: umbilical cord-derived mesenchymal stem cell; ALI: acute lung injury; EAE: experimental autoimmune encephalomyelitis; hESCs: human embryonic stem cells; hP-MSCs-EVs: human placental mesenchymal stem cellsderived EVs; hUCMSC-Ex: human umbilical cord MSC-derived exosomes; cGVHD: chronic Graft-Versus-Host Disease; aGVHD: acute graft-versus-host disease; cDCs: the CD8a conventional dendritic cells; IDO-BMSCs: BMSCs which stably expressed IDO; CIA: collagen-induced arthritis; NCI: nerve crush injury: MRI: magnetic resonance imaging; PSNL: partial sciatic nerve ligation; $\mathrm{CCl}$ : chronic constriction nerve injury model; ADMSC: adipose tissue derived mesenchymal stem cells; PMF: pulsed magnetic field; DPSCs: Dental pulp-derived stem cells; SNI: spared nerve injury; TBI: traumatic brain injury; DAH: diffuse alveolar hemorrhage; MuSCs: muscle stem cells; SCI: spinal cord injury; hUCSC-EV: Human umbilical cord mesenchymal stem cell-derived extracellular vesicles; EAE: experimental autoimmune encephalomyelitis; PF: Pulmonary fibrosis; RA: Rheumatoid arthritis; hUCMSC-sEVs: hUCMSC-derived small extracellular vesicles (sEVs)

\section{Abbreviations}

PNI: Peripheral nerve injuries; MSCs: Mesenchymal stem cells; TNF-a: Tumor necrosis factor-a; IL: Interleukin; IFN: Interferon; TGF: Transforming growth factor; HO: Heme oxygenase; HGF: Hepatocyte growth factor; NO: Nitricoxide; HLA-G5: Human leucocyte antigen-G5; PGE: Prostaglandin E; NK: Natural killer; DCs: Dendritic cells; exos: Exosomes; SCs: Schwann cells; LN: Lymph nodes; TLR: Toll like receptor; Treg cells: Regulatory T cells; GDNF: Glial cell derived neurotrophic factor; $\mathrm{CXCL}$ : Cysteine-X-cysteine chemokine ligand; CCL: Cellular components chemokine ligand; BMSCs: Bone marrow-derived mesenchymal stem cells; ADMSCs: Adipose tissue derived mesenchymal stem cells; GM-CSF: Granulocyte-macrophage colony-stimulating factor; NF-kB: Nuclear factor-kB; SCl: Spinal cord injury; Teffs: Effector T cells; WJ: Wharton's jelly; DP: Dental pulp; PBMCs: Peripheral blood monocytes; TSG-6: Tumor-necrosis-factor-inducible gene 6 protein; PR: Progesterone receptor; GR: Glucocorticoid receptors; hUC-MSCs: Human umbilical cord-derived mesenchymal stem cells; TBI: Traumatic brain injuries; COX: Cyclooxygenase; ANAs: Acellular nerve allografts; XANGs: Xenogeneic acellular nerve grafts; EPI-NCSCs: Epidermal neural crest stems cells; ECM: Extracellular matrix; PLGA: Polylactic co glycolic acid; EVs: Extracellular vesicles; OE-MSCs: Olfactory ecto-MSCs; IBD: Inflammatory bowel disease; IUAs: Intrauterine adhesions; ALI: Acute lung injury; EAE: Experimental autoimmune encephalomyelitis; hESCs: Human embryonic stem cells; hP-MSCs-EVs: Human placental mesenchymal stem cells-derived EVs; hUCMSC-Ex: Human umbilical cord MSC-derived exosomes; mTOR: Mammalian target of rapamycin; CGVHD: Chronic Graft-Versus-Host Disease; aGVHD: Acute graft-versus-host disease; CDCs: The CD8a conventional dendritic cells; IDO-BMSCs: BMSCs which stably expressed IDO; CIA: Collagen-induced arthritis; NCI: Nerve crush injury; MRI: Magnetic resonance imaging; Foxp3: Forkhead box protein P 3; PSNL: Partial sciatic nerve ligation; CCI: Chronic constriction nerve injury model; PMF: Pulsed magnetic field; DPSCs: Dental pulp-derived stem cells; SNI: Spared nerve injury; TBI: Traumatic brain injury; DAH: Diffuse alveolar hemorrhage; MuSCs: Muscle stem cells; hUCSC-EV: Human umbilical cord mesenchymal stem cell-derived extracellular vesicles; PF: Pulmonary fibrosis; RA: Rheumatoid arthritis.

\section{Acknowledgements}

We thank Prof. Yu Wang (Institute of Orthopedics) for her patient guidance in revising this review. And this work was supported by Medical Research and Development Projects (AWS17J005).

\section{Authors' contributions}

JST performed most of the overall work for this report. YW, JP contributed to the review of mesenchymal stem cell therapy as co-corresponding authors. LXL contributed to the review of mesenchymal stem cell applications in peripheral nerve injury. YJG, FQM, CCL contributed to the review of animal studies concerning mesenchymal stem cell therapy and wrote much of this manuscript. TYZ, JYL, JZ contributed to the review of the history of mesenchymal stem cell therapy in different diseases. SFC, YLL, QW contributed to the review of the application aspects of mesenchymal stem cell therapy. All authors read and approved the final manuscript.

\section{Funding}

This work was supported by Medical Research and Development Projects (AWS17J005).

\section{Availability of data and materials}

Not applicable.

\section{Declarations}

\section{Ethics approval and consent to participate}

Not applicable.

\section{Consent for publication}

Not applicable.

\section{Competing interests}

The authors declare that they have no competing interests.

\section{Author details}

${ }^{1}$ The Fourth Medical Center of Chinese PLA General Hospital, Beijing 100853, People's Republic of China. ${ }^{2}$ Institute of Orthopedics, Chinese PLA General Hospital, Beijing Key Lab of Regenerative Medicine in Orthopedics, Key Laboratory of Musculoskeletal Trauma \& War Injuries PLA, Beijing 100853, People's Republic of China. ${ }^{3}$ Department of Stomatology, First Medical Center, Chinese PLA General Hospital, Beijing 100853, People's Republic of China. ${ }^{4} T$ The School of Medicine, Jinzhou Medical University, Jinzhou 121099, People's Republic of China. ${ }^{5}$ Department of Spine Surgery, Peking University People's Hospital, Beijing 100044, People's Republic of China. ${ }^{6}$ The School of Medicine, Nankai University, Tianjin 300071, People's Republic of China. 
Received: 22 October 2021 Accepted: 18 December 2021

Published online: 15 January 2022

\section{References}

1. Siemionow M, Brzezicki G. Current techniques and concepts in peripheral nerve repair. Int Rev Neurobiol. 2009;87:141-72.

2. Chen Z, Pradhan S, Liu C, Le L. Skin-derived precursors as a source of progenitors for cutaneous nerve regeneration. Stem Cells. 2012:30:2261-70.

3. Liang $X$, Ding $Y$, Zhang $Y$, Tse $H$, Lian Q. Paracrine mechanisms of mesenchymal stem cell-based therapy: current status and perspectives. Cell Transplant. 2014;23:1045-59.

4. Ying W, Wehling M, Samengo G, Tidball JG. Increases of M2a macrophages and fibrosis in aging muscle are influenced by bone marrow aging and negatively regulated by muscle-derived nitric oxide. Aging Cell. 2015;14

5. Kiguchi N, Kobayashi Y, Saika F, Sakaguchi H, Maeda T, Kishioka S. Peripheral interleukin-4 ameliorates inflammatory macrophagedependent neuropathic pain. Pain. 2015;156:684.

6. Lu JY, Cao Q, Zheng D, Yan S, Wang Y. Discrete functions of M2a and $\mathrm{M} 2 \mathrm{C}$ macrophage subsets determine their relative efficacy in treating chronic kidney disease. Kidney Int. 2013;84

7. Lu C, Wang B, Zhang P, Han S, Pi W, Kou YH, et al. Combining chitin biological conduits with small autogenous nerves and platelet-rich plasma for the repair of sciatic nerve defects in rats. CNS Neurosci Ther. 2021;27:805-19.

8. Zhou G, Chang W, Zhou X, Chen Y, Dai F, Anwar A, et al. Nanofibrous nerve conduits with nerve growth factors and bone marrow stromal cells pre-cultured in bioreactors for peripheral nerve regeneration. ACS Appl Mater Interfaces. 2020;12:16168-77.

9. Liu C, Yin G, Sun Y, Lin YF, Xie Z, English AW, et al. Effect of exosomes from adipose-derived stem cells on the apoptosis of Schwann cells in peripheral nerve injury. CNS Neurosci Ther. 2020;26:189-96.

10. Faroni A, Mobasseri SA, Kingham PJ, Reid AJ. Peripheral nerve regeneration: experimental strategies and future perspectives. Adv Drug Deliv Rev. 2015:82-83:160-7.

11. Bjorklund G, Anderson T, Stabenfeldt S. Recent advances in stem cell therapies to address neuroinflammation, stem cell survival, and the need for rehabilitative therapies to treat traumatic brain injuries. Int J Mol Sci. 2021;22.

12. Zackoinflamma SD, Butler PE, Kalaskar DM. Current progress in use of adipose derived stem cells in peripheral nerve regeneration. World $J$ Stem Cells. 2015;7:51015.

13. Noone C, Kihm A, English K, O'Dea S, Mahon B. IFN- $\gamma$ stimulated human umbilical-tissue-derived cells potently suppress NK activation and resist NK-mediated cytotoxicity in vitro. Stem Cells Dev. 2013;22:3003-14.

14. Li N, Hua J. Interactions between mesenchymal stem cells and the immune system. Cell Mol Life Sci. 2017;74:2345-60.

15. Selmani Z, Naji A, Zidi I, Favier B, Gaiffe E, Obert L, et al. Human leukocyte antigen-G5 secretion by human mesenchymal stem cells is required to suppress $T$ lymphocyte and natural killer function and to induce CD4+CD25highFOXP3+ regulatory T cells. Stem Cells. 2008:26:212-22

16. Siniscalco D, Giordano C, Galderisi U, Luongo L, Alessio N, Bernardo $G$, et al. Intra-brain microinjection of human mesenchymal stem cells decreases allodynia in neuropathic mice. Cell Mol Life Sci. 2010:67:655-69.

17. Fattore A, Luciano R, Pascucci L, Li W, Tang Y, Wei X, et al. Immunoregulatory effects of mesenchymal stem cell-derived extracellular vesicles on T lymphocytes. Cell Transplant. 2015;24:2615-27.

18. Rotshenker S. Wallerian degeneration: the innate-immune response to traumatic nerve injury. J Neuroinflamm. 2011:8:1-14.

19. Mietto BS, Mostacada K, Martinez AM. Neurotrauma and inflammation: CNS and PNS responses. Mediators Inflamm. 2015;2015:251204.

20. Chen C, Weber J, Holtkamp S, Ince LM, de Juan A, Wang C, et al. Loss of direct adrenergic innervation after peripheral nerve injury causes lymph node expansion through IFN- $\gamma$. J Exp Med. 2021;218.

21. Maiko O, Masaki H, Nobuhisa N, et al. Transplantation of dental pulp stem cells suppressed inflammation in sciatic nerves by promoting macrophage polarization towards anti-inflammation phenotypes and ameliorated diabetic polyneuropathy. J Diabetes Investig. 2016:7:485-96

22. Pan D, Hunter DA, Schellhardt L, Jo S, Santosa KB, Larson EL, et al. The accumulation of $T$ cells within acellular nerve allografts is length-dependent and critical for nerve regeneration. Exp Neurol. 2019;318:216-31.

23. Aggarwal S. Human mesenchymal stem cells modulate allogeneic immune cell responses. Blood. 2005;105:1815.

24. Kim DS, Jang IK, Lee MW, et al. Enhanced immunosuppressive properties of human mesenchymal stem cells primed by interferon- $\gamma$. EBioMedicine. 2018;28:261-73.

25. Domenis R, Cifù A, Quaglia S, Pistis C, Moretti M, Vicario A, et al. Pro inflammatory stimuli enhance the immunosuppressive functions of adipose mesenchymal stem cells-derived exosomes. Sci Rep. 2018;8:13325.

26. Fregnan F, Muratori L, Simões A, Giacobini-Rob MG, Raimondo S. Role of inflammatory cytokines in peripheral nerve injury. Neural Regen Res. 2012;7:2259.

27. Wu R, Chen B, Jia X, Qiu Y, Liu M, Huang C, et al. Interleukin-1B influences functional regeneration following nerve injury in mice through nuclear factor-KB signaling pathway. Immunology. 2019;156:235-48.

28. Shamash S, Reichert F, Rotshenker S. The cytokine network of Wallerian degeneration: tumor necrosis factor-alpha, interleukin-1alpha, and interleukin-1beta. J Neurosci. 2002:22:3052

29. Nadeau S, Filali M, Zhang J, Kerr B, Rivest S, Soulet D, et al. Functional recovery after peripheral nerve injury is dependent on the pro-inflammatory cytokines IL-1 $\beta$ and TNF: implications for neuropathic pain. J Neurosci. 2011:31:12533-42

30. Boivin A, Pineau I, Barrette B, Filali M, Vallières $N$, Rivest $S$, et al. Toll-like receptor signaling is critical for Wallerian degeneration and functional recovery after peripheral nerve injury. J Neurosci. 2007;27:12565-76.

31. Chen G, Park CK, Xie RG, Ji RR. Intrathecal bone marrow stromal cells inhibit neuropathic pain via TGF- $\beta$ secretion. J Clin Investig. 2015;125:3226-40.

32. Turner M, Feldmann M. Comparison of patterns of expression of tumour necrosis factor, lymphotoxin and interleukin-6 mRNA. Biochem Biophys Res Commun. 1988;153:1144-51.

33. Tsarouchas $M$, Wehner $D$, Cavone L, Munir T, Keatinge $M$, Lambertus $M$, et al. Dynamic control of proinflammatory cytokines II- $1 \beta$ and Tnf-a by macrophages in zebrafish spinal cord regeneration. Nat Commun. 2018;9:4670.

34. Putra A, Ridwan FB, Putridewi Al, Kustiyah AR, Wirastuti K, Sadyah $N A C$, et al. The role of TNF- $a$ induced MSCs on suppressive inflammation by increasing TGF- $\beta$ and IL-10. Open Access Maced J Med Sci. 2018;6:1779-83.

35. Beldi G, Khosravi M, Abdelgawad ME, Salomon BL, Uzan G, Haouas H, et al. TNFa/TNFR2 signaling pathway: an active immune checkpoint for mesenchymal stem cell immunoregulatory function. Stem Cell Res Ther. 2020;11:281

36. Beldi G, Bahiraii S, Lezin C, Nouri Barkestani M, Abdelgawad ME, Uzan G, et al. TNFR2 is a crucial hub controlling mesenchymal stem cell biological and functional properties. Front Cell Dev Biol. 2020;8.

37. Peng RJ, Jiang $B$, Ding XP, Huang $H$, Liao Y, Peng $G$, et al. Effect of TNF-a inhibition on bone marrow-derived mesenchymal stem cells in neurological function recovery after spinal cord injury via the Wnt signaling pathway in a rat model. Cell Physiol Biochem. 2017;42:743-52.

38. Spangler J, Tomala J, Luca V, Jude K, Dong S, Ring A, et al. Antibodies to interleukin-2 elicit selective $T$ cell subset potentiation through distinct conformational mechanisms. Immunity. 2015:42:815-25.

39. Reichert F, Levitzky R, Rotshenker S. Interleukin 6 in intact and injured mouse peripheral nerves. Eur J Neurosci. 2010:8:530-5.

40. Ge Y, Zhang Y, Tang Q, Gao J, Yang H. Mechanisms of the immunomodulation effects of bone marrow-derived mesenchymal stem cells on facial nerve injury in sprague-dawley rats. Stem Cells Dev. 2019.

41. Eliana B, Gina G, Oscar H, González J, Echeverria V, Ashraf GM, et al. Mitochondrial neuroglobin is necessary for protection induced by conditioned medium from human adipose-derived mesenchymal stem cells in astrocytic cells subjected to scratch and metabolic injury. Mol Neurobiol. 2019;56:5167-87. 
42. Erriah M, Pabreja K, Fricker M, Baines KJ, Donnelly LE, Bylund J, Karlsson A, Simpson JL. Galectin-3 enhances monocyte-derived macrophage efferocytosis of apoptotic granulocytes in asthma. Respir Res. 2019;20:1. https://doi.org/10.1186/s12931-018-0967-9.

43. Kalinski AL, Yoon C, Huffman LD, et al. Analysis of the immune response to sciatic nerve injury identifies efferocytosis as a key mechanism of nerve debridement. Elife. 2020;9:e60223.

44. Hercus TR, Thomas D, Guthridge MA, Ekert PG, King-Scott J, Parker MW, Lopez AF. The granulocyte-macrophage colony-stimulating factor receptor: linking its structure to cell signaling and its role in disease. Blood. 2009;114:1289-98.

45. Jones $C E$, Chan K. Interleukin-17 stimulates the expression of interleukin-8, growth-related oncogene-alpha, and granulocyte-colonystimulating factor by human airway epithelial cells. Am J Respir Cell Mol Biol. 2002;26:748-53.

46. Day YJ, Liou JT, Lee CM, Lin YC, Mao CC, Chou AH, et al. Lack of interleukin-17 leads to a modulated micro-environment and amelioration of mechanical hypersensitivity after peripheral nerve injury in mice. Pain. 2014;155:1293-302.

47. Ferretti S, Bonneau O, Dubois GR, Jones CE, Trifilieff A. IL-17, produced by lymphocytes and neutrophils, is necessary for lipopoly-saccharideinduced airway neutrophilia: IL-15 as a possible trigger. J Immunol. 2003;15:2106-12.

48. Kleinschnitz C, Hofstetter $\mathrm{H}$, Meuth $\mathrm{G}$, Braeuninger S, Sommer C, Stoll G. T cell infiltration after chronic constriction injury of mouse sciatic nerve is associated with interleukin-17 expression. Exp Neurol. 2006:200:480-5.

49. Kong X, Gao J. Macrophage polarization: a key event in the secondary phase of acute spinal cord injury. J Cell Mol Med. 2017;21(5):941-54.

50. Wynn T, Vannella K. Macrophages in tissue repair, regeneration, and fibrosis. Immunity. 2016;44:450-62.

51. Wang AYL, Loh CYY, Shen HH, Hsieh SY, Wang IK, Lee CM, et al. Human Wharton's jelly mesenchymal stem cell-mediated sciatic nerve recovery is associated with the upregulation of regulatory T cells. Int J Mol Sci. 2020:21:6310.

52. Mantovani A, Biswas SK, Galdiero MR, Sica A, Locati M. Macrophage plasticity and polarization in tissue repair and remodelling. J Pathol. 2013:229:176-85.

53. Siqueira MB, Kroner A, Girolami El, Santos-Nogueira E, Zhang J, David S. Role of IL-10 in resolution of inflammation and functional recovery after peripheral nerve injury. J Neurosci. 2015;35:16431-42.

54. Ydens E, Cauwels A, Asselbergh B, Goethals S, Peeraer L, Lornet G, et al. Acute injury in the peripheral nervous system triggers an alternative macrophage response. J Neuroinflamm. 2012;9:176.

55. Obermajer N, Popp F, Soeder Y, Haarer J, Geissler E, Schlitt H, et al. Conversion of Th17 into IL-17A(neg) regulatory T cells: a novel mechanism in prolonged allograft survival promoted by mesenchymal stem cell-supported minimized immunosuppressive therapy. I Immunol. 2014;193:4988-99.

56. Cui Y, Xu N, Xu W, Xu G. Mesenchymal stem cells attenuate hydrogen peroxide-induced oxidative stress and enhance neuroprotective effects in retinal ganglion cells. Vitro Cell Dev Biol Anim. 2017;53:328-35.

57. Liao CF, Chen CC, Lu YW, Yao CH, Lin JH, Way TD, et al. Effects of endogenous inflammation signals elicited by nerve growth factor, interferon- $\gamma$, and interleukin- 4 on peripheral nerve regeneration. J Biol Eng. 2019;13:86.

58. Zhang J, Chen H, Duan Z, Chen K, Liu Z, Zhang L, et al. The effects of co-transplantation of olfactory ensheathing cells and schwann cells on local inflammation environment in the contused spinal cord of rats. Mol Neurobiol. 2017;54:943-53.

59. Ullah I, Choe YH, Khan M, Bharti D, Shivakumar, SB, Lee HJ, et al. Dental pulp-derived stem cells can counterbalance peripheral nerve injuryinduced oxidative stress and supraspinal neuro-infammation in rat brain. Sci Rep. 2018;8.

60. Yagura $\mathrm{K}$, et al. The enhancement of CCL2 and CCL5 by human bone marrow-derived mesenchymal stem/stromal cells might contribute to inflammatory suppression and axonal extension after spinal cord injury. PLOS ONE. 2020;15(3):e0230080.

61. Mosser D, Edwards J. Exploring the full spectrum of macrophage activation. Nat Rev Immunol. 2008;8:958-69.
62. Kiguchi N, Kobayashi Y, Saika F, Kishioka S. Epigenetic upregulation of CCL2 and CCL3 via histone modifications in infiltrating macrophages after peripheral nerve injury. Cytokine. 2013;64:666-72.

63. Zhang Z, Zhang ZY, Wu Y, Schluesener HJ. Lesional accumulation of CD163+ macrophages/microglia in rat traumatic brain injury. Brain Res. 2012;1461:102-10.

64. Peruzzaro S, Andrews M, Al-Gharaibeh A, Pupiec O, Resk M, Story D, et al. Transplantation of mesenchymal stem cells genetically engineered to overexpress interleukin-10 promotes alternative inflammatory response in rat model of traumatic brain injury. J Neuroinflamm. 2019;16:2.

65. Zhong Z, Chen A, Fa Z, et al. Bone marrow mesenchymal stem cells upregulate PI3K/AKT pathway and down-regulate NF-KB pathway by secreting glial cell-derived neurotrophic factors to regulate microglial polarization and alleviate deafferentation pain in rats. Neurobiol Dis. 2020;143:104945.

66. Heo JS, Choi Y, Kim HO. Adipose-derived mesenchymal stem cells promote M2 macrophage phenotype through exosomes. Stem Cells Int. 2019;2019:7921760

67. Xu C, Fu F, Li X, Zhang S. Mesenchymal stem cells maintain the microenvironment of central nervous system by regulating the polarization of macrophages/microglia after traumatic brain injury. Int J Neurosci. 2017;127:1124-35.

68. Chen X, Wei Q, Sun H, Qian H, Zhang X, Shen L, et al. Exosomes derived from human umbilical cord mesenchymal stem cells regulate macrophage polarization to attenuate systemic lupus erythematosus-associated diffuse alveolar hemorrhage in mice. Int J Stem Cells. 2021;14:331-40.

69. Ma H, Li YN, Song L, Liu R, Li X, Shang Q, et al. Macrophages inhibit adipogenic differentiation of adipose tissue derived mesenchymal stem/stromal cells by producing pro-inflammatory cytokines. Cell Biosci. 2020;10:88.

70. Sharif O, Bolshakov VN, Raines S, Newham P, Perkins ND. Transcriptional profiling of the LPS induced NF-kB response in macrophages. BMC Immunol. 2007;8:1.

71. Marwick JA, Mills R, Kay O, Michail K, Stephen J, Rossi AG, et al. Neutrophils induce macrophage anti-inflammatory reprogramming by suppressing NF-KB activation. Cell Death Dis. 2018;9:665.

72. Burzyn D, Kuswanto W, Kolodin D, Shadrach JL, Cerletti M, Jang Y, et al. A special population of regulatory T cells potentiates muscle repair. Cell. 2013;155:1282-95.

73. Meisel R, Zibert A, Laryea M, Göbel U, Däubener W, Dilloo D. Human bone marrow stromal cells inhibit allogeneic T-cell responses by indoleamine 2,3-dioxygenase-mediated tryptophan degradation. Blood. 2004;103:4619-21

74. Cafferty W, Gardiner N, Das P, Qiu J, McMahon S, Thompson S. Conditioning injury-induced spinal axon regeneration fails in interleukin-6 knock-out mice. J Neurosci. 2004;24:4432-43.

75. Siniscalco D, Giordano C, Galderisi U, Luongo L, de Novellis V, Rossi F, et al. Long-lasting effects of human mesenchymal stem cell systemic administration on pain-like behaviors, cellular, and biomolecular modifications in neuropathic mice. Front Integr Neurosci. 2011;5:79.

76. Pan D, Hunter DA, Schellhardt L, Fuchs A, Halevi AE, Snyder-Warwick AK, et al. T cells modulate IL-4 expression by eosinophil recruitment within decellularized scaffolds to repair nerve defects. Acta Biomater. 2020;112:149-63.

77. Chiossone L, Conte R, Spaggiari GM, Serra M, Romei C, Bellora F, et al. Mesenchymal stromal cells induce peculiar alternatively activated macrophages capable of dampening both innate and adaptive immune responses. Stem Cells. 2016:34:1909-21.

78. Yu Y, Valderrama AV, Han Z, Uzan G, Naserian S, Oberlin E. Human fetal liver MSCs are more effective than adult bone marrow MSCs for their immunosuppressive, immunomodulatory and Foxp3+ T Regs induction capacity. Stem Cell Res Ther. 2020;12:138.

79. Wang M, Yang Y, Yang D, Luo F, Liang W, Guo S, et al. The immunomodulatory activity of human umbilical cord blood-derived mesenchymal stem cells in vitro. Immunology. 2009;126:220-32.

80. Zhang L, Wang XY, Zhou PJ, He Z, Yan HZ, Xu DD, et al. Use of immune modulation by human adipose-derived mesenchymal stem cells to treat experimental arthritis in mice. Am J Transl Res. 2017;9:2595-607. 
81. Jung MK, Kwak JE, Shin EC. IL-17A-producing Foxp3(+) regulatory T cells and human diseases. Immune Netw. 2017;17:276-86.

82. Sakaguchi S, Vignali DA, Rudensky AY, Niec RE, Waldmann H. The plasticity and stability of regulatory T cells. Nat Rev Immunol. 2013;13:461-7.

83. Valencia X, Stephens G, Goldbach-Mansky R, Wilson M, Shevach EM, Lipsky PE. TNF downmodulates the function of human CD4+CD25hi T-regulatory cells. Blood. 2006;108:253-61.

84. Kourko O, Seaver K, Odoardi N, Basta S, Gee K. IL-27, IL-30, and IL-35: a cytokine triumvirate in cancer. Front Oncol. 2019;9:969.

85. Zhang B, Su Y, Zhou J, Zheng Y, Zhu D. Toward a better regeneration through implant-mediated immunomodulation: harnessing the immune responses. Adv Sci. 2021;8:e2100446.

86. Pradier A, Passweg J, Villard J, Kindler V. Human bone marrow stromal cells and skin fibroblasts inhibit natural killer cell proliferation and cytotoxic activity. Cell Transplant. 2011;20:681-91.

87. Sotiropoulou PA, Perez SA, Gritzapis AD, Baxevanis CN, Papamichail M. Interactions between human mesenchymal stem cells and natural killer cells. Stem Cells. 2006;24:74-85.

88. Fu Q, Man X, Yu M, Chu Y, Luan X, Piao H, et al. Human decidua mesenchymal stem cells regulate decidual natural killer cell function via interactions between collagen and leukocyte-associated immunoglobulin-like receptor 1. Mol Med Rep. 2017;16:2791-8.

89. Fan L, Yu Z, Li J, Dang X, Wang K. Immunoregulation effects of bone marrow-derived mesenchymal stem cells in xenogeneic acellular nerve grafts transplant. Cell Mol Neurobiol. 2014;34(7):999-1010.

90. Yue L, Yao D, Zhang J, Liu B, Zhang L, Hua F, et al. The effects of epidermal neural crest stem cells on local inflammation microenvironment in the defected sciatic nerve of rats. Front Mol Neurosci. 2017;10:133.

91. Harrell CR, Jankovic MG, Fellabaum C, Volarevic A, Djonov V, Arsenijevic $A$, et al. Molecular mechanisms responsible for anti-inflammatory and immunosuppressive effects of mesenchymal stem cell-derived factors. Adv Exp Med Biol. 2019;1084:187-206.

92. Zhou Y, Day A, Haykal S, Keating A, Waddell TK. Mesenchymal stromal cells augment $\mathrm{CD} 4+$ and $\mathrm{CD} 8+\mathrm{T}$-cell proliferation through a CCL2 pathway. Cytotherapy. 2013;15:1195-207.

93. Ma Y, Dong L, Zhou D, Cai J, Zhang X, Liang J, et al. Extracellular vesicles from human umbilical cord mesenchymal stem cells improve nerve regeneration after sciatic nerve transection in rats. J Cell Mol Med. 2019;23:2822-35.

94. Sheng Y, Zhou X, Wang J, et al. MSC derived EV loaded with miRNA-22 inhibits the inflammatory response and nerve function recovery after spinal cord injury in rats. J Cell Mol Med. 2021:25(21):10268-78.

95. Xu K, Ma D, Zhang G, Movassaghpour A, Yousefi M. Human umbilical cord mesenchymal stem cell-derived small extracellular vesicles ameliorate collagen-induced arthritis via immunomodulatory T lymphocytes. Mol Immunol. 2021;135:36-44.

96. Zhai X, Chen K, Yang H, Li B, Zhou T, Wang H, et al. Extracellular vesicles derived from CD73 modified human umbilical cord mesenchymal stem cells ameliorate inflammation after spinal cord injury. J Nanobiotechnol. 2021;19:274.

97. Marta G, Estela V, Rafael S, Christian M, Maria C, Pilar S, et al. HIF-1a and pro-inflammatory signaling improves the immunomodulatory activity of MSC-derived extracellular vesicles. Int J Mol Sci. 2021;22:3416.

98. Martinez VG, Ontoria-Oviedo I, Ricardo CP, Harding SE, Sacedon R, Varas A, et al. Overexpression of hypoxia-inducible factor 1 alpha improves immunomodulation by dental mesenchymal stem cells. Stem Cell Res Ther. 2017;8:208.

99. Cosenza S, Toupet K, Maumus M, Luz-Crawford P, Blanc-Brude O, Jorgensen C, et al. Mesenchymal stem cells-derived exosomes are more immunosuppressive than microparticles in inflammatory arthritis. Theranostics. 2018;8:1399-410.

100. Tian J, Zhu Q, Zhang Y, Bian Q, Hong Y, Shen Z, et al. Olfactory ectomesenchymal stem cell-derived exosomes ameliorate experimental colitis modulating Th1/Th17 and treg cell responses. Front Immunol. 2020;11:598322.

101. Duan L, Huang H, Zhao X, Zhou M, Chen S, Wang C, et al. Extracellular vesicles derived from human placental mesenchymal stem cells alleviate experimental colitis in mice by inhibiting inflammation and oxidative stress. Int J Mol Med. 2020;46:1551-61.

102. Fang J, Zhang S, Liu Z, Pan Y, Cao L, Hou P, et al. Skeletal muscle stem cells confer maturing macrophages anti-inflammatory properties through insulin-like growth factor-2. Stem Cells Transl Med. 2020;9:773-85.

103. Xin L, Lin X, Zhou F, Li C, Wang X, Yu H, et al. A scaffold laden with mesenchymal stem cell-derived exosomes for promoting endometrium regeneration and fertility restoration through macrophage immunomodulation. Acta Biomater. 2020;1 13:252-66.

104. Witte SFH, Merino AM, Franquesa M, Strini T, van Zoggel JAA, et al. Cytokine treatment optimises the immunotherapeutic effects of umbilical cord-derived MSC for treatment of inflammatory liver disease. Stem Cell Res Ther. 2017;8:140.

105. Lv H, Yuan X, Zhang J, Lu T, Yao J, Zheng J, et al. Heat shock preconditioning mesenchymal stem cells attenuate acute lung injury via reducing NLRP3 inflammasome activation in macrophages. Stem Cell Res Ther. 2021;12:290.

106. Vigo T, Rocca C, Faicchia D, Procaccini C, Ruggieri M, Salvetti M, et al. IFNß enhances mesenchymal stromal (Stem) cells immunomodulatory function through STAT1-3 activation and mTOR-associated promotion of glucose metabolism. Cell Death Dis. 2019;10:85.

107. Ahmadvand S, Absalan A, Azadi D. Human umbilical cord mesenchymal stem cell-derived extracellular vesicles attenuate experimental autoimmune encephalomyelitis via regulating pro and anti-inflammatory cytokines. Sci Rep. 2021;11:11658.

108. Wu J, Song D, Li Z, Guo B, Xiao Y, Liu W, et al. Immunity-and-matrixregulatory cells derived from human embryonic stem cells safely and effectively treat mouse lung injury and fibrosis. Cell Res. 2020;30:794-809.

109. He X, Dong Z, Cao Y, Wang H, Liu S, Liao L, et al. MSC-derived exosome promotes M2 polarization and enhances cutaneous wound healing. Stem Cells Int. 2019;2019:7132708.

110. Helena H, Cardoso RS, Zonari A, Correia J, Leal EC, Jiménez-Balsa A, et al. The kinetics of small extracellular vesicle delivery impacts skin tissue regeneration. ACS Nano. 2019;13:8694-707.

111. Teixeira GQ, Pereira CL, Ferreira JR, Maia AF, Gomez-Lazaro M, Barbosa MA, et al. Immunomodulation of human mesenchymal stem/stromal cells in intervertebral disc degeneration: insights from a proinflammatory/degenerative ex vivo model. Spine. 2018;43:1673-82.

112. Shen B, Liu J, Zhang F, Wang Y, Qin Y, Zhou Z, et al. CCR2 Positive exosome released by mesenchymal stem cells suppresses macrophage functions and alleviates ischemia/reperfusion-induced renal injury. Stem Cells Int. 2016;2016:1240301.

113. Wang B, Jia H, Zhang B, Wang J, Ji C, Zhu X, et al. Pre-incubation with hucMSC-exosomes prevents cisplatin-induced nephrotoxicity by activating autophagy. Stem Cell Res Ther. 2017;8:75.

114. Lai P, Chen X, Guo L, Wang Y, Liu X, Liu Y, et al. A potent immunomodulatory role of exosomes derived from mesenchymal stromal cells in preventing CGVHD. J Hematol Oncol. 2018;11:135.

115. Li KL, Li JY, Xie GL, Ma XY. Exosomes released from human bone marrow-derived mesenchymal stem cell attenuate acute graft-versus-host disease after allogeneic hematopoietic stem cell transplantation in mice. Front Cell Dev Biol. 2021;9:617589.

116. He J, Li B, Zhou L, Shen B, Zhao H, Peng K, et al. Indoleamine 2,3-dioxgenase-transfected mesenchymal stem cells suppress heart allograft rejection by increasing the production and activity of dendritic cells and regulatory T cells. J Investig Med. 2020;68:728-37.

117. Ma D, Xu K, Zhang G, Liu Y, Gao J, Tian M, et al. Immunomodulatory effect of human umbilical cord mesenchymal stem cells on T lymphocytes in rheumatoid arthritis. Int Immunopharmacol. 2019;74:105687.

118. Yang Z, Zheng C, Zhang F, Lin B, Cao M, Tian X, et al. Magnetic resonance imaging of enhanced nerve repair with mesenchymal stem cells combined with microenvironment immunomodulation in neurotmesis. Muscle Nerve. 2020;61:815-25.

119. Schäfer S, Berger JV, Deumens R, Goursaud S, Hanisch UK, Hermans E. Influence of intrathecal delivery of bone marrow-derived mesenchymal stem cells on spinal inflammation and pain hypersensitivity in a rat model of peripheral nerve injury. J Neuroinflammation. 2014;11:157.

120. Mert T, Kurt A, Altun I, Celik A, Baran F, Gunay I. Pulsed magnetic field enhances therapeutic efficiency of mesenchymal stem cells in chronic neuropathic pain model. Bioelectromagnetics. 2017;38:255-64. 
121. Omi M, Hata M, Nakamura N, Miyabe M, Kobayashi Y, Kamiya H, et al. Transplantation of dental pulp stem cells suppressed inflammation in sciatic nerves by promoting macrophage polarization towards antiinflammation phenotypes and ameliorated diabetic polyneuropathy. J Diabetes Investig. 2016;7:485-96.

122. Shiue S, Rau R, Shiue H, Hung YW, Li ZX, Yang KD, et al. Mesenchymal stem cell exosomes as a cell-free therapy for nerve injury-induced pain in rats. Pain. 2019;160:210-23.

123. Tsuruta T, Sakai K, Watanabe J, Katagiri W, Hibi H. Dental pulp-derived stem cell conditioned medium to regenerate peripheral nerves in a novel animal model of dysphagia. PLoS ONE. 2018;13:e0208938.

124. Zhang R, Liu Y, Yan K, Yin D, Li F, Wu Y, et al. Anti-inflammatory and immunomodulatory mechanisms of mesenchymal stem cell transplantation in experimental traumatic brain injury. J Neuroinflammation. 2013;10:106.

125. Chen X, Wei Q, Sun H, Talebi M, Mehdizadeh A, Yousefi M. Exosomes derived from human umbilical cord mesenchymal stem cells regulate macrophage polarization to attenuate systemic lupus erythematosusassociated diffuse alveolar hemorrhage in mice. Int J Stem Cells. 2021; 14:331-40.

126. Luo Z, Lin J, Sun Y, Wang C, Chen J. Bone marrow stromal cell-derived exosomes promote muscle healing following contusion through macrophage polarization. Stem Cells Dev. 2021;30:135-48.

127. Bao CS, Li XL, Liu L, Wang B, Yang FB, Chen LG. Transplantation of Human umbilical cord mesenchymal stem cells promotes functional recovery after spinal cord injury by blocking the expression of IL-7. Eur Rev Med Pharmacol Sci. 2018;22:6436-47.

128. Tang Z, Gao J, Wu J, Chen CY, Rao SS, Yin H, et al. Human umbilical cord mesenchymal stromal cells attenuate pulmonary fibrosis via regulatory T cell through interaction with macrophage. Stem Cell Res Ther. 2021;12:397.

129. Naserian S, Shamdani S, Arouche N, Uzan G. Regulatory T cell induction by mesenchymal stem cells depends on the expression of TNFR2 by T cells. Stem Cell Res Ther. 2020;11:534

130. Schilling BK, Schusterman MA, Kim DY, Repko AJ, Klett KC, Christ GJ, et al. Adipose 8 erived stem cells delay muscle atrophy after peripheral nerve injury in the rodent model. Muscle Nerve. 2019.

131. Saeidi M, Masoud A, Shakiba Y, Hadjati J, Bonab MM, Nicknam MH et al. Immunomodulatory effects of human umbilical cord Wharton's jelly-derived mesenchymal stem cells on differentiation, maturation and endocytosis of monocyte-derived dendritic cells. Iranian J Allergy Asthma Immunol. 2013;12:37-49.

132. Jiang $L$, Jones $S$, Jia X. Stem cell transplantation for peripheral nerve regeneration: current options and opportunities. Int J Mol Sci. 2017

133. Kubiak C, Grochmal J, Kung T, Cederna P, Midha R, Kemp S, et al. Stemcell-based therapies to enhance peripheral nerve regeneration. Muscle Nerve. 2020;61:449-59.

134. Liaudanskaya V, Jgamadze D, Berk A, Bischoff D, Gu B, Hawks-Mayer H, et al. Engineering advanced neural tissue constructs to mitigate acute cerebral inflammation after brain transplantation in rats. Biomaterials. 2019:192:510-22.

\section{Publisher's Note}

Springer Nature remains neutral with regard to jurisdictional claims in published maps and institutional affiliations.

Ready to submit your research? Choose BMC and benefit from:

- fast, convenient online submission

- thorough peer review by experienced researchers in your field

- rapid publication on acceptance

- support for research data, including large and complex data types

- gold Open Access which fosters wider collaboration and increased citations

- maximum visibility for your research: over $100 \mathrm{M}$ website views per year

At BMC, research is always in progress.

Learn more biomedcentral.com/submissions 